\title{
Infectious complications following heart transplantation in the era of high-priority allocation and extracorporeal membrane oxygenation
}

Stéphanie Pons ${ }^{1}$, Romain Sonneville ${ }^{1,2^{*}}$, Lila Bouadma ${ }^{1,3}$, Lenka Styfalova ${ }^{4}$, Stéphane Ruckly ${ }^{4}$, Mathilde Neuville', Aguila Radjou' ${ }^{1}$, Jordane Lebut ${ }^{1}$, Marie-Pierre Dilly ${ }^{5}$, Bruno Mourvillier ${ }^{1,3}$, Richard Dorent ${ }^{6}$, Patrick Nataf ${ }^{6}$, Michel Wolff ${ }^{1}$ and Jean-François Timsit ${ }^{1,3}$

\begin{abstract}
Background: Infectious complications are a major cause of morbidity and mortality after heart transplantation (HT). However, the epidemiology and outcomes of these infections in the recent population of adult heart transplant recipients have not been investigated.

Methods: We conducted a single-center retrospective study on infectious complications occurring within 180 days following HT on consecutive heart transplant recipients, from January 2011 to June 2015 at Bichat University Hospital in Paris, France. Risk factors for non-viral infections occurring within 8, 30 and 180 days after HT were investigated using competing risk analysis.
\end{abstract}

Results: Overall, 113 patients were included. Fifty-eight (51\%) HTs were high-priority allocations. Twenty-eight (25\%) patients had an extracorporeal membrane oxygenation (ECMO) support at the time of transplantation. Ninety-two (81\%) patients developed at least one infection within 180 days after HT. Bacterial and fungal infections ( $n=181$ episodes) occurred in 80 (71\%) patients. The most common bacterial and fungal infections were pneumonia $(n=95 / 181$ episodes, 52\%), followed by skin and soft tissue infections ( $n=26 / 181,14 \%)$. Multi-drug-resistant bacteria were responsible for infections in 21 (19\%) patients. Viral infections were diagnosed in 44 (34\%) patients, mostly Cytomegalovirus infection $(n=39,34 \%)$. In multivariate subdistribution hazard model, prior cardiac surgery (subdistribution hazard ratio $\mathrm{sHR}=2.7[95 \% \mathrm{Cl} 1.5-4.6] p<0.01)$ and epinephrine or norepinephrine at the time of HT (sHR $=2.3[95 \%$ Cl 1.1-5.2] $p=0.04$ ) were significantly associated with non-viral infections within 8 days after HT. Prior cardiac surgery $(\mathrm{sHR}=2.5[95 \% \mathrm{Cl} 1.4-4.4] p<0.01)$, recipient age over 60 years (sHR $=2.0[95 \% \mathrm{Cl} 1.2-3.3] p<0.01)$ and ECMO following $\mathrm{HT}(\mathrm{sHR}=1.7[95 \% \mathrm{Cl} 1.0-2.8] p=0.04$ ) were significantly associated with non-viral infection within 30 days after HT, as well as within 180 days after HT.

Conclusion: This study confirmed the high rate of infections following HT. Recipient age, prior cardiac surgery and ECMO following HT were independent risk factors for early and late bacterial and fungal infections.

Keywords: Heart transplantation, Infections, Extracorporeal membrane oxygenation, Outcome

\footnotetext{
*Correspondence: romain.sonneville@aphp.fr

${ }^{1}$ Medical and Infectious Diseases Intensive Care Unit, AP-HP, Bichat-

Claude Bernard University Hospital, 46 rue Henri Huchard, 75877 Paris

Cedex, France

Full list of author information is available at the end of the article
} 


\section{Introduction}

Heart transplantation (HT) is the gold standard treatment of end-stage cardiac failure [1]. Substantial changes have recently occurred in the epidemiology of HT, including older patients and more high-priority allocations for critically ill patient [2-4]. Moreover, ventricular assist device (VAD) as a bridge to $\mathrm{HT}$ and extracorporeal membrane oxygenation (ECMO) support before and after HT has significantly increased in the last years [5]. Despite a high incidence of infections in these immunocompromised patients, recent data describing their epidemiology following HT are scarce. Most studies in adult heart transplant recipients conducted years ago reported an incidence of bacterial infections of $20-30 \%$ [6-11]. More recently, studies have found a $9-45 \%$ Cytomegalovirus (CMV) infection rate $[7,11-14]$. Infections in heart transplant recipients represent a real challenge, as they are responsible for increased morbidity, mortality, length of stay and associated costs $[6,7]$. Moreover, many changes in patient care have occurred in the last decade, including new immunosuppressive protocols, advances in early infection diagnosis and multi-drug-resistant pathogens emergence. Understanding the current epidemiology of infections and their clinical impact on outcome may help to better prevent and treat patients in the future.

The purpose of this study was to describe the epidemiology and outcomes of infections occurring within 180 days after HT. Specifically, we aimed to determine risk factors for non-viral infections occurring within 8 , 30 and 180 days following HT.

\section{Materials and methods}

\section{Patient population and study design}

This single-center retrospective study was conducted at Bichat-Claude Bernard Hospital, Paris, France. We included all consecutive adult heart transplant recipients between January 1, 2011, and June 30, 2015. Data on donors and recipients were retrieved from the medical records and the French Transplant Agency database "Cristal," which is a prospectively maintained database designed to store all the donors and recipients' data. The French Intensive Care Society Ethics Committee approved the study (CE SRLF17-10). Data on intensive care unit (ICU) management and infections were retrospectively collected. In accordance with French law, all the patients or next of kin were informed of the possibility to use their hospitalization's data for clinical research and gave their consent.

\section{Immunosuppressive and antimicrobial prophylaxis after transplantation}

Immunosuppressive treatment and antimicrobial prophylaxis for heart transplant recipient are well codified in our transplantation center, in accordance with the International Society of Heart and Lung Transplantation (ISHLT) guidelines [15]. All patients received intraoperative methylprednisolone and mycophenolate mofetil intravenous boli, and an early postoperative induction therapy with either antithymocyte globulins or basiliximab. Then, a triple maintenance therapy with calcineurin inhibitors, mycophenolate mofetil and steroids was administered. For highly sensitized patients, plasma exchanges before and/or after HT were realized.

Intraoperative antibiotic prophylaxis was cefazolin except otherwise decided (ongoing infection or multidrug-resistant (MDR) bacterium colonization). The patients were systematically screened for methicillinresistant Staphylococcus aureus or extended spectrum beta lactamase (ESBL) producing Enterobacteriaceae carriage before HT. Postoperative prophylaxis against infections was initiated between day 3 and day 7 after heart transplantation. Postoperative cotrimoxazole was administered for Pneumocystis jiroveci pneumonia and toxoplasmosis prevention for a duration varying from 1 year to lifelong, depending on the risk (i.e., immunosuppressive regimen, toxoplasmosis mismatch). Oral amphotericin B was given to all patients within 30 days after HT in the absence of intestinal disease. CMV disease prevention consisted in antiviral prophylaxis with valganciclovir for high-risk patients (donor positive/recipient negative for CMV). For CMV seropositive patients or CMV seronegative donors and recipients, the preemptive strategy based on the level of plasmatic CMV copies was chosen (threshold $4 \log ^{10}$ copies $/ \mathrm{mL}$ ). In case of treated acute rejection, valganciclovir prophylaxis was systematically administered in CMV seropositive recipients, associated with cotrimoxazole prophylaxis in case of interruption. Heart transplant recipients received, if possible, influenza and pneumococcal vaccines before heart transplantation, or within the first year following the transplantation, as recommended by our local protocol.

\section{Clinical definitions}

Infections were defined as per the CDC guidelines [16]. The definitions of infectious complications in heart transplant recipients also followed the 2010 ISHLT work and the American Society of Transplantation recommendations [17, 18]. Only microbiologically documented infections were included in the analysis. MDR bacteria 
included lack of susceptibility to one or more agents in three or more antimicrobial categories active against the isolated bacteria [19]. CMV infection was defined as CMV virus detected by viral culture or quantitative PCR assay for CMV in any body fluid or tissue specimen. Primary CMV infection was defined as the first detection of CMV infection in an individual who had no evidence of CMV exposure before transplantation and was classified as CMV infection. CMV disease was defined as the presence of appropriate clinical symptoms and/or signs together with documentation of $\mathrm{CMV}$ in tissue from the relevant organ [20]. Diagnosis of proven or probable invasive fungal infection was based on histopathological findings or blood/tissue culture. All the infectious complications occurring within 180 days after HT were recorded. Primary and secondary graft dysfunctions were defined according to the ISHLT consensus conference on primary graft dysfunction after cardiac transplantation [21]. Thus, failure to wean from the extracorporeal circulation at the end of the surgery or need of a circulatory support by ECMO within $24 \mathrm{~h}$ after HT defined a severe graft dysfunction. Acute rejection was defined according to the original ISHLT Heart Biopsy Grading Scale [22].

\section{Statistical analysis}

Quantitative parameters are reported as median and interquartile range [IQR 25-75 percentile] and qualitative parameters as number and percentage. Univariate and multivariate analyses were performed to assess for associations between potential risk factors and non-viral infections within 8, 30 and 180 days after HT using a Fine and Gray subdistribution hazard model considering death as a competing risk. Factors included in the multivariate model were selected among variables yielding $p$ values smaller than 0.10 in univariate analysis and adjusted on the sequential organ failure assessment at the time of HT. Subdistribution hazard ratio (sHR) and 95\% confidence interval (95\% CIs) were estimated for significant risk factors, based on a multivariate analysis. The impact of infectious complications treated as timedependent events on mortality at 90 days after HT was determined using Cox regression models. Statistics were performed using SAS 9.4 and $\mathrm{R}$ softwares, and a $p$ value of 0.05 or lower was considered significant.

\section{Results}

\section{Patients}

Overall, 113 patients underwent HT between January 1, 2011, and June 30, 2015, at Bichat-Claude Bernard Hospital, Paris. All those patients were included in the study, with no lost to follow-up within 180 days after HT. Patient's baseline characteristics are given in Table 1. Fifty-eight (51\%) HTs were national high-priority
Table 1 Heart transplant recipient baseline characteristics

\begin{tabular}{|c|c|}
\hline Characteristics & $\begin{array}{l}\text { Heart transplant } \\
\text { recipients } \\
(n=113)\end{array}$ \\
\hline Recipient gender, male; $n(\%)$ & $86(76)$ \\
\hline Recipient age, years; median [IQR] & $53[40 ; 62]$ \\
\hline Prior diabetes mellitus; $n(\%)$ & $24(21)$ \\
\hline Prior cardiac surgery (VAD surgery excluded); $n$ (\%) & $27(24)$ \\
\hline $\mathrm{BMI}, \mathrm{kg} / \mathrm{m}^{2} ;$ median $[\mathrm{IQR}]$ & $24,4[22,1 ; 27,8]$ \\
\hline Serum creatinine $(\mu \mathrm{mol} / \mathrm{l})$; median $[\mathrm{IQR}]$ & $130[99 ; 158]$ \\
\hline \multicolumn{2}{|l|}{ Etiology of heart failure; $n(\%)$ : } \\
\hline Dilated cardiomyopathy & $50(44)$ \\
\hline Ischemic cardiomyopathy & $44(39)$ \\
\hline Hypertrophic cardiomyopathy & $8(7)$ \\
\hline Others & $11(10)$ \\
\hline \multicolumn{2}{|l|}{ Recipient location right before HT; n (\%) } \\
\hline Home & $34(30)$ \\
\hline Medical/surgical units & $14(12)$ \\
\hline Intermediate care units & $21(19)$ \\
\hline Intensive care units & $44(39)$ \\
\hline \multicolumn{2}{|l|}{ Length of stay before HT, days; median [IQR] } \\
\hline Hospital & $11[6 ; 19]$ \\
\hline Intermediate or intensive care units & $8[5 ; 14]$ \\
\hline Donor age, years; median [IQR] & $45[37 ; 42]$ \\
\hline Donor gender, male; $n$ (\%) & $67(59)$ \\
\hline CMV mismatch (D+/R-); $n(\%)$ & $15(13)$ \\
\hline VAD before HT; $n(\%)$ & $20(18)$ \\
\hline ECMO before HT; $n(\%)$ & $28(25)$ \\
\hline SOFA score at time of HT; median [IQR] & $4[1 ; 6]$ \\
\hline National high-priority allocation; $n$ (\%) & $58(51)$ \\
\hline Cold ischemia time, minutes; median [IQR] & $190[140 ; 210]$ \\
\hline Plasma exchanges after HT; $n(\%)$ & $20(18)$ \\
\hline
\end{tabular}

$B M I$ body mass index, $C M V$ cytomegalovirus, $D$ donor, ECMO extracorporeal membrane oxygenation, $H T$ heart transplantation, $R$ recipient, SOFA score sequential organ failure assessment score, $V A D$ ventricular assist device

allocations. Patients were predominantly males $(n=86$, $76 \%$ ), with a median age of $53[40 ; 62]$ years. Main causes of cardiac failure were dilated cardiomyopathy $(n=50$, $44 \%)$ and ischemic cardiomyopathy $(n=44,39 \%)$. Most patients $(n=79,70 \%)$ were already hospitalized at the time of HT, including a large number in the ICU $(n=44$, $39 \%)$. Twenty (18\%) patients had VAD as a bridge to transplantation, and 28 (25\%) patients were under ECMO support at the time of HT.

\section{Epidemiology and etiologies of infectious complications}

Twenty (18\%) patients of our cohort, including six VAD patients, had an infection within 8 days before heart transplantation. However, device infection was the main reason for bridging them to transplantation in only two cases. Twenty-two (19\%) patients received an antibiotic 
therapy for an ongoing infection or an alternative prophylaxis other than cefazolin during heart transplantation, preferentially targeting ESBL $(n=6)$, Staphylococci $(n=6)$, Pseudomonas aeruginosa $(n=3)$, other Gramnegative bacilli $(n=4)$ and other pathogens $(n=3)$. Ninety-two (81\%) patients developed at least one infection within 180 days after HT. There were 181 episodes of bacterial and fungal infections occurring in 80 (71\%) patients. Fifty-five (49\%) patients had at least one bacterial infection within 8 days after HT. Although bacteria were the most common identified pathogens in the early postoperative phase, viruses also accounted for a high proportion of infections between 8 and 30 days following HT (Fig. 1). Data on infections and outcomes in heart transplant recipients within 180 days after heart transplantation are described in Table 2. The most common bacterial and fungal infections were pneumonia ( $n=95 / 181$ infectious episodes, $52 \%$ ), followed by skin and soft tissue infections $(n=26,14 \%)$. We recorded 30 bloodstream infections (BSI) occurring after a median time of 10 [5-21] days following heart transplantation. Of these BSIs, $12 / 30$ (40\%) were secondary to another infection (pneumonia $n=4$, catheter-related infection $n=3$, cannulas-related infection $n=3$, intra-abdominal infection $n=2)$ and 18/30 (60\%) were of unknown origin. Six out of eighteen patients with BSI of unknown origin were under ECMO.

Within 180 days after HT, 63 (56\%) patients developed at least one infection caused by Gram-negative bacilli. Enterobacteriaceae were the most common bacteria responsible for infections within 8 days after HT (22 patients, 20\%). Bacterial infections due to Pseudomonas aeruginosa preferentially occurred after 8 days following HT. Thirty-five (31\%) patients developed at least one infection due to Gram-positive cocci, mostly Enterococcus spp. (19 patients, 17\%). Twenty-two (19\%) patients were colonized by a MDR bacterium before transplantation, and $6(5 \%)$ acquired one during the first 8 days in the ICU. Nine $(8 \%)$ colonized patients developed at least one infection due to the same MDR microorganism during their ICU stay. Overall, MDR bacteria were responsible for infections in 21 (19\%) patients, mostly ESBL $(n=14,12 \%)$. Sixteen patients presented at least one invasive fungal infection. Aspergillus spp. were responsible for invasive infection in $6(5 \%)$ patients, in all cases over 30 days following HT. Candida spp. were considered responsible for infection in $4(4 \%)$ patients. Viral infections were diagnosed in $44(39 \%)$ patients, mostly CMV infection ( $n=39,34 \%)$, occurring preferentially between 8 and 30 days after HT (Fig. 1). All CMV infections were asymptomatic and treated preemptively, according to the level of plasmatic CMV copies.

\section{Risk factors for postoperative non-viral infections}

The pre-, intra- and postoperative patients' characteristics with at least one bacterial or fungal infection or without any non-viral infection within 8,30 and 180 days after HT were firstly compared by univariate analysis

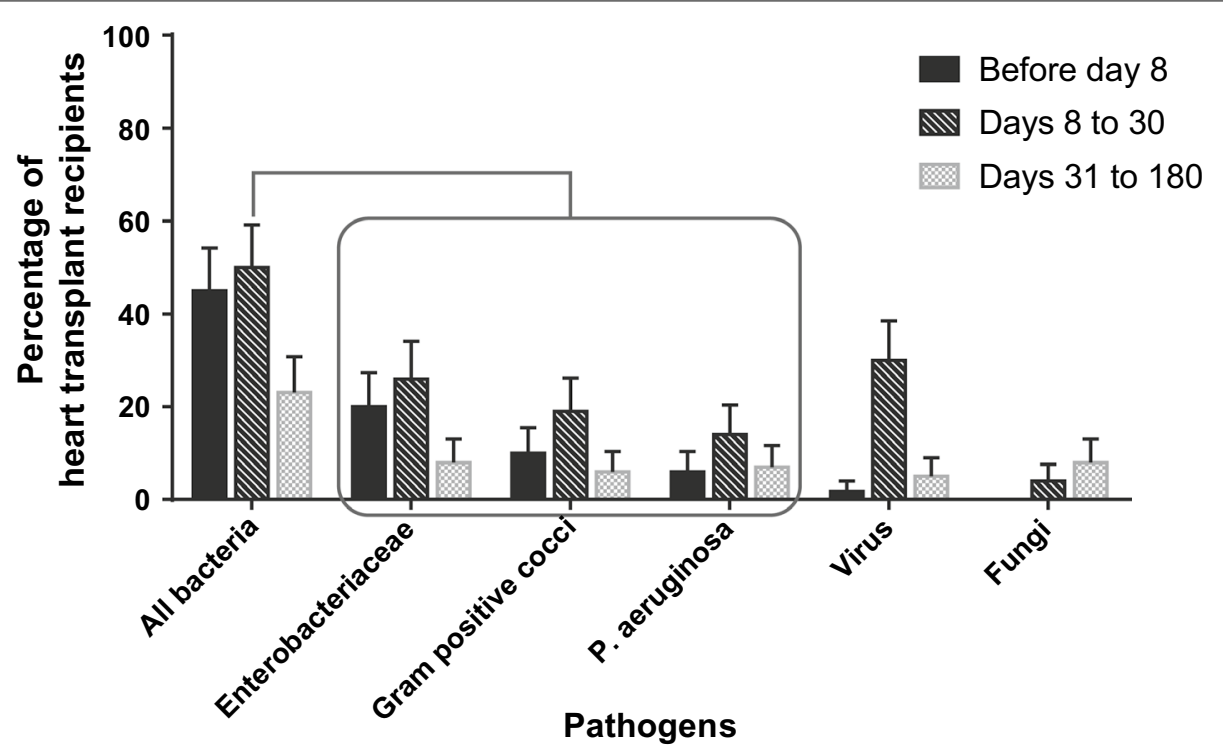

Fig. 1 Percentage of adult heart transplant recipients $(n=113)$ infected by different pathogens according to the postoperative period (before day 8 , days 8 to 30 and days 31 to $180^{*}$. *A same patient can have been infected multiple times by the same pathogen and during different time periods 
Table 2 Infectious complications and outcomes in heart transplant recipients within 180 days after heart transplantation

\begin{tabular}{|c|c|}
\hline Events & Overall population $(n=113)$ \\
\hline Deaths; $n(\%)$ & $19(17)$ \\
\hline $\begin{array}{l}\text { Patients with } \geq 1 \text { post-transplant } \\
\text { infection(s) of all pathogens; } n(\%)\end{array}$ & $92(81)$ \\
\hline $\begin{array}{l}\text { Number of post-transplant non-viral } \\
\text { infectious episodes }\end{array}$ & 181 \\
\hline \multicolumn{2}{|l|}{$\begin{array}{l}\text { Site of non-viral infections; } n \text { (\% infec- } \\
\text { tious episodes) }\end{array}$} \\
\hline Respiratory tract & $95(52)$ \\
\hline Skin and soft tissues & $26(14)$ \\
\hline Urinary tract & $22(12)$ \\
\hline $\begin{array}{l}\text { Bloodstream infection of unknown } \\
\text { origin }\end{array}$ & $18(10)$ \\
\hline Secondary bloodstream infections & $12(7)$ \\
\hline Mediastinitis & $11(6)$ \\
\hline Catheter-related infection & $8(4)$ \\
\hline Other ${ }^{b}$ & $13(7)$ \\
\hline \multicolumn{2}{|l|}{$\begin{array}{l}\text { Patients with at least an infection caused } \\
\text { by; } n(\%)^{c}\end{array}$} \\
\hline Overall bacteria and fungi & $80(71)$ \\
\hline Gram-negative bacilli & $63(56)$ \\
\hline Enterobacteriaceae & $50(44)$ \\
\hline P. aeruginosa & $24(21)$ \\
\hline Gram-positive cocci & $35(31)$ \\
\hline S. aureus & $4(3)$ \\
\hline Enterococci & $19(17)$ \\
\hline Streptococci & $10(9)$ \\
\hline Multi-drug-resistant bacteria & $21(19)$ \\
\hline Fungi & $16(14)$ \\
\hline Candida spp. & $4(4)$ \\
\hline Aspergillus spp. & $6(5)$ \\
\hline Other $^{d}$ & $6(5)$ \\
\hline Patients with a viral infection; $n$ (\%) & $44(39)$ \\
\hline CMV infection & $39(34)$ \\
\hline HSV infection & $10(9)$ \\
\hline $\begin{array}{l}\text { Patients with treated acute rejection; } \\
n(\%)\end{array}$ & $24(21)$ \\
\hline
\end{tabular}

Multi-drug-resistant bacteria: lack of susceptibility to one or more agents in three or more antimicrobial categories active against the isolated bacteria CMV cytomegalovirus, HSV herpes simplex virus

a One episode could be counted multiple times according to the number of infectious sites

b Other infections: 8 gastrointestinal tract infections, 2 central nervous system infections and 3 other infections

c A same patient could have been infected by different germs during the same period

d Other invasive fungal infections: (Fusarium spp. $n=1$, Pneumocystis jiroveci $n=1$, Microsporidium spp. $n=1$, Trichosporon spp. $n=1$, undefined yeast $n=2$ )
(Additional file 1: Table S1). All non-viral infections diagnosed within 8 days following HT were bacterial infections. There was no significant difference in the induction and maintenance immunosuppressive regimen between groups. In multivariate analysis, prior cardiac surgery (VAD excluded) $(\mathrm{sHR}=2.7[95 \% \mathrm{CI} 1.5-4.6] p<0.01)$ and epinephrine or norepinephrine continuous infusion at the time of HT $(\mathrm{sHR}=2.3[95 \% \mathrm{CI} 1.1-5.2] p=0.04)$ were significantly associated with the occurrence of bacterial infection within 8 days after HT. Within 30 days after $\mathrm{HT}$, prior cardiac surgery (VAD excluded) $(\mathrm{sHR}=2.5$ [95\% CI 1.4-4.4] $p<0.01$ ), recipient age over 60 years $(\mathrm{sHR}=2.0[95 \% \mathrm{CI} 1.2-3.3] p<0.01)$ and $\mathrm{ECMO}$ within $24 \mathrm{~h}$ after HT $(\mathrm{sHR}=1.7$ [95\% CI 1.0-2.8] $p=0.04)$ were significantly associated with bacterial and fungal infections. Lastly, within 180 days after HT, prior cardiac surgery $(\mathrm{sHR}=2.3$ [95\% CI 1.3-4.0] $p<0.01)$, recipient age over 60 years $(\mathrm{sHR}=1.8[95 \% \mathrm{CI} 1.1-3.1] p=0.02)$ and ECMO within $24 \mathrm{~h}$ after HT (sHR $=1.6$ [95\% CI 1.0-2.7]) $p=0.05)$ were significantly associated with non-viral infections (Table 3 ).

\section{Incidence of early severe graft dysfunctions}

Fifty-nine (52\%) patients developed an early severe graft dysfunction and needed an ECMO circulatory support within $24 \mathrm{~h}$ after HT. Data analysis revealed that among those patients, $47(42 \%)$ had a severe primary graft dysfunction and $12(11 \%)$ a secondary graft dysfunction due to acute rejection, hemorrhagic shock or pericardial tamponade. Forty-seven $(80 \%)$ patients with ECMO were weaned from the circulatory support, while 12 patients (20\%) died under support.

\section{Outcomes within 180 days after HT}

The median ICU length of stay after HT was 16 [1123] days, and the median hospital length of stay after HT was 34 [25-46] days. Ninety-four (83\%) patients were alive 180 days after HT, and 8 out to 19 (42\%) deaths were deemed to be caused by an infectious complication (pneumonia, $n=6$, and intra-abdominal infection, $n=2$ ). Bacterial infections in the ICU were associated with a longer stay in the ICU (20 days [95\% CI 13-29] versus 12 days [95\% CI 8-17] $p<0.001$ ), but not associated with mortality. In an adjusted Cox model, the third non-viral infection was significantly associated with death at 90 days after HT (adjusted HR 6.2 [95\% CI 1.2-31], $p=0.02$ ). 
Table 3 Multivariate Fine and Gray analysis of risk factors associated with the occurrence of bacterial and fungal infections within 8 days, 30 days and 180 days after heart transplantation adjusted on SOFA score at the time of heart transplantation

\begin{tabular}{|c|c|c|c|c|c|c|c|c|c|}
\hline \multirow[t]{2}{*}{ Parameter } & \multicolumn{3}{|c|}{ Within 8 days after HT } & \multicolumn{3}{|c|}{ Within 30 days after HT } & \multicolumn{3}{|c|}{ Within 180 days after HT } \\
\hline & SHR & $\begin{array}{l}\mathbf{9 5 \%} \\
\text { CI }\end{array}$ & $p$ value & SHR & $\begin{array}{l}95 \% \\
\text { CI }\end{array}$ & $p$ value & SHR & $95 \%$ CI & $p$ value \\
\hline $\begin{array}{l}\text { Recipient age over } \\
60 \text { years }\end{array}$ & & & & 2.0 & $1.2-3.3$ & $<0.01$ & 1.8 & $1.1-3.1$ & 0.02 \\
\hline $\begin{array}{l}\text { Prior cardiac } \\
\text { surgery (VAD } \\
\text { excluded) }\end{array}$ & 2.7 & $1.5-4.6$ & $<0.01$ & 2.5 & $1.4-4.4$ & $<0.01$ & 2.3 & $1.3-4.0$ & $<0.01$ \\
\hline $\begin{array}{l}\text { Antibiotic } \\
\text { treatment for } \\
\text { bacterial infection } \\
\text { at the time of HT }\end{array}$ & 0.3 & $0.2-0.7$ & $<0.01$ & & & & & & \\
\hline $\begin{array}{l}\text { Epinephrine or } \\
\text { Norepinephrine at } \\
\text { the time of HT }\end{array}$ & 2.3 & $1.1-5.2$ & 0.04 & & & & & & \\
\hline ECMO after HT & & & & 1.7 & $1.0-2.8$ & 0.04 & 1.6 & $1.0-2.7$ & 0.05 \\
\hline
\end{tabular}

ECMO extracorporeal membrane oxygenation, $H T$ heart transplantation, SOFA score sequential organ failure assessment score, VAD ventricular assist device *Only significant variables with $p$-value $<0.1$ in the univariate model and SOFA score at time of heart transplantation were included in the multivariate model

\section{Discussion}

We conducted a large single-center retrospective study to describe the epidemiology, risk factors and outcomes of infections occurring within 180 days after HT, in the era of high-priority allocations and mechanical support by ECMO and VAD. To our knowledge, it is the largest single-center cohort of recent adult heart transplant recipients analyzed for infections and their impact on prognosis. We found a very high rate of infections within 180 days after HT $(n=92,81 \%)$, mostly bacterial or fungal infections $(n=80,71 \%)$. Moreover, we identified four factors associated with non-viral infections depending on the postoperative period: hemodynamic instability at the time of HT, prior cardiac surgery, recipient age over 60 years and early circulatory support by ECMO following HT. According to the literature, the cumulative incidence of infections following HT varies from 30 to $80 \%$, depending on the definitions of infections and the chosen interval time after HT [7, 10, 23, 24]. However, these studies have included different populations of recipients, as ECMO and VAD as a bridge to transplantation and national high-priority allocations were not as developed.
Recently, Héquet et al. have showed in a national cohort study that $43 \%$ of the heart transplant recipients developed at least one bacterial or Candida infection within 1 year after HT. Interestingly the population in this study was different from ours as a higher proportion of the patients had a VAD before transplantation ( $18 \%$ vs $30 \%$ [11]. In a recent cohort of pediatric heart transplant recipients, the authors demonstrated that $80 \%$ of the population had at least one infection following HT, but the mean period of follow-up was 5.3 years. In the same study, the instantaneous risk of acquisition of the first bacterial infection was the highest within 30 days following HT [25].

The most common bacterial and fungal infections in our study were pneumonia (52\%) followed by skin and soft tissue infections (14\%) in agreement with the literature $[7,10,24]$. The microbiological spectrum of infections did not differ from previous studies, Gram-negative bacilli being responsible for the majority of bacterial infections [10, 26, 27]. Our study also confirmed the increased incidence of MDR bacteria responsible for both carriage and infections before and after HT [28]. 
We showed that recipient age over 60 years, prior cardiac surgery (VAD excluded) and ECMO within $24 \mathrm{~h}$ after HT were risk factors associated with non-viral infections within 30 and 180 days after HT. Interestingly, VAD before HT and national high-priority allocation were not associated with infections following HT. National highpriority allocation criteria depend on the countries, but are everywhere designated for candidates on the waiting list who have the highest priority on the basis of medical urgency. However, in our study, hemodynamic instability at the time of HT, in the context of national high-priority allocation or not, was an independent risk factor for bacterial infection within 8 days after HT. Besides, recent papers showed that VAD before HT did not increase the risk of post-transplant infection [5, 11]. ECMO within $24 \mathrm{~h}$ after HT is considered as a severe graft failure, according to the ISHLT definition [21]. In our cohort, the incidence of ECMO support following HT was very high (52\%). The criteria for a severe primary graft failure were found in 47 patients (42\%). This incidence is higher than the one described in the literature (20\% to $30 \%)[29$, 30]. In France, the last national annual report recorded a recent increase in primary graft failure, with an incidence around 38\% [31]. Age of both the donor and the recipient, ventilator dependence and ECMO at the time of HT, allosensitization before HT and cold ischemia time are known to be risk factors for primary graft failure [21, 29, 30,32,33]. Yet, those characteristics were not significantly associated with the occurrence of infections in our cohort of heart transplant recipients. Thus, ECMO following HT as a risk factor for early non-viral infection could be directly due to the external mechanical support but also to the recipient's underlying condition, the donor's characteristics and the surgery. Finally, prior cardiac surgery was already known as a potential risk factor for mortality from bacterial infection but not directly as a risk factor for bacterial infection [25].

Specific risk factors for invasive fungal infections would have been interesting to look for, as ECMO has already been described as an important risk factor in a HT population [34]. As we described only sixteen invasive fungal infections in our cohort, it would have been difficult to draw any conclusion on potential risk factors.

CMV infection was the predominant viral infection, occurring in $34 \%$ of the population. This rate is in accordance with recent studies focused on CMV [13, 14, 35]. However, the retrospective design of our study may represent an important source of bias for identification of symptomatic CMV disease, as symptoms such as diarrhea or isolated fever may have been missed. This high rate of CMV infections should be a prior concern, as it has been recently proved that CMV infection without any criteria of CMV disease could also be responsible for a reduction in 10-year cardiac allograft vasculopathy-free survival in heart transplant recipients [13, 35].

There was no difference in immunosuppressive regimen between patients developing or not infections after HT. However, the high rate of infections in our cohort was also a direct consequence of immunosuppressive therapies. In the current era of HT, those results enlighten the need of personalized immunosuppression, adjusted on patient's risk factors for acute rejection and early infections [36, 37].

The overall mortality at 6 months after HT (17\%) was in accordance with published data $[4,5,33,38]$. Bacterial infections in the ICU were associated with an increased length of stay but not with mortality. In the literature, infectious complications after HT have been responsible for increased length of stay and healthcare costs in adults but also with increased mortality in children $[7,11,25]$.

The first strength of this study was the inclusion of consecutive heart transplant recipients in a transplantation specialized center, in the era of VAD and ECMO mechanical supports and of increased rate of high-priority allocations. The detailed description of epidemiology, risk factors and outcomes of infectious complications in this new population could be a good tool for clinicians taking care of adult heart transplant recipients. We also acknowledge that the present study has several limitations. First, our peculiar population does probably not reflect the reality of all cardiac transplant centers, as the majority of enrolled patients were national high-priority allocations already hospitalized in ICU at the time of HT. It might be difficult to extend these results to all the patients on heart transplant waiting list. Moreover, the sample size is limited, yet it is a recent single-center study. We did not study the donor-derived infections even though it would have been of interest to better characterize early bacterial infections following heart transplantation. As the data collection was retrospective, potential inaccuracies in data reporting could exist. A few infectious episodes were also missing data, most notably the bacterial etiology of infection. Finally, strategies for perioperative management of heart transplant recipients may differ among institutions and may be considered a source of bias.

\section{Conclusion}

This study confirmed the high rate of infections occurring within 180 days after HT in adult recipients. Recipient age, prior cardiac surgery, hemodynamic instability at the time of HT and ECMO following HT were independent risk factors for early and late non-viral infections. Thus, the recent pre- and post-transplant recipient characteristics modification could be directly correlated with 
infections following HT. A prospective study could be of interest to better determine risk factors for infections following HT.

\section{Additional file}

Additional file 1: Table S1. Pre-, intra- and postoperative characteristics of heart transplant recipients without non-viral infection and patients developing at least one bacterial or fungal infection within 8 days, 30 days and 180 days after $\mathrm{HT}$

\section{Abbreviations}

95\% Cl: 95\% confidence interval; BSI: bloodstream infection; CMV: cytomegalovirus; ECMO: extracorporeal membrane oxygenation; ESBL: extended spectrum beta lactamase; HT: heart transplantation; ICU: intensive care unit; ISHLT: International Society of Heart and Lung Transplantation; VAD: ventricular assist device; MDR: multi-drug-resistant; sHR: subdistribution hazard ratio.

\section{Authors' contributions}

SP and RS had full access to all the data in the study and take responsibility for the integrity of the data and the accuracy of the data analysis. SL and SR did the statistical analysis of the data. SP, RS, LB, MN, AR, JL, MPD, BM, RD, PN, MX, JFT contributed to the study design, data analysis and interpretation, and the writing of the manuscript. All authors read and approved the final manuscript.

\section{Author details}

${ }^{1}$ Medical and Infectious Diseases Intensive Care Unit, AP-HP, Bichat-Claude Bernard University Hospital, 46 rue Henri Huchard, 75877 Paris Cedex, France. 2 UMR 1148, LVTS, Sorbonne Paris Cité, Inserm/Paris Diderot University, Paris, France. ${ }^{3}$ UMR 1137, IAME Team 5, DeSCID: Decision Sciences in Infectious Diseases Prevention, Control and Care, Sorbonne Paris Cité, Inserm/Paris Diderot University, Paris, France. ${ }^{4}$ Department of Biostatistics, ICUREsearch, Paris, France. ${ }^{5}$ Department of Anesthesiology, AP-HP, Bichat-Claude Bernard University Hospital, Paris, France. ${ }^{6}$ Department of Cardiac Surgery, AP-HP, Bichat-Claude Bernard University Hospital, Paris, France.

\section{Acknowledgements}

We thank HUPNVS (Hôpitaux Universitaires Paris Nord Val de Seine) for their support, all the patients who participated in the cohort study, the central data managers of the Cristal database and all the investigators involved in the study.

\section{Competing interests}

The authors declare that they have no competing interests.

\section{Availability of data and materials}

The datasets used and/or analyzed during the current study are available from the corresponding author on reasonable request.

\section{Consent for publication}

Not applicable.

\section{Ethics approval and consent to participate}

Informed consent to participate was obtained from participants or next of kin. The French Intensive Care Society Ethics Committee approved the study (reference CE SRLF17-10).

\section{Funding}

No financial support or any material support has been received to conduct this study.

\section{Publisher's Note}

Springer Nature remains neutral with regard to jurisdictional claims in published maps and institutional affiliations.
Received: 29 September 2018 Accepted: 12 January 2019

Published online: 25 January 2019

\section{References}

1. Mehra MR, Canter CE, Hannan MM, Semigran MJ, Uber PA, Baran DA, et al. The 2016 international society for heart lung transplantation listing criteria for heart transplantation: a 10-year update. J Heart Lung Transpl. 2016;35(1):1-23.

2. Alraies MC, Eckman P. Adult heart transplant: indications and outcomes. J Thorac Dis. 2014;6(8):1120-8.

3. Davis MK, Hunt SA. State of the art: cardiac transplantation. Trends Cardiovasc Med. 2014;24(8):341-9.

4. Stehlik J, Edwards LB, Kucheryavaya AY, Benden C, Christie JD, Dipchand $\mathrm{Al}$, et al. The registry of the international society for heart and lung transplantation: 29th official adult heart transplant report-2012. J Heart Lung Transpl. 2012;31(10):1052-64.

5. Kirklin JK, Cantor R, Mohacsi P, Gummert J, De By T, Hannan MM, et al. First annual IMACS report: a global international society for heart and lung transplantation registry for mechanical circulatory support. J Heart Lung Transpl. 2016:35(4):407-12.

6. Roussel JC, Baron O, Périgaud C, Bizouarn P, Pattier S, Habash O, et al. Outcome of heart transplants 15 to 20 years ago: graft survival, posttransplant morbidity, and risk factors for mortality. J Heart Lung Transpl. 2008;27(5):486-93.

7. van de Beek D, Kremers WK, Del Pozo JL, Daly RC, Edwards BS, McGregor CGA, et al. Effect of infectious diseases on outcome after heart transplant. Mayo Clin Proc. 2008;83(3):304-8.

8. Rajagopal K, Lima B, Petersen RP, Mesis RG, Daneshmand MA, Lemaire A, et al. Infectious complications in extended criteria heart transplantation. J Heart Lung Transpl. 2008;27(11):1217-21.

9. Snydman DR. Epidemiology of infections after solid-organ transplantation. Clin Infect Dis. 2001;1(33 Suppl 1):S5-8.

10. Mattner F, Fischer S, Weissbrodt H, Chaberny IF, Sohr D, Gottlieb J, et al. Post-operative nosocomial infections after lung and heart transplantation. J Heart Lung Transpl. 2007;26(3):241-9.

11. Héquet D, Kralidis G, Carrel T, Cusini A, Garzoni C, Hullin R, et al. Ventricular assist devices as bridge to heart transplantation: impact on post-transplant infections. BMC Infect Dis. 2016:8(16):321.

12. Ramanan $P$, Razonable RR. Cytomegalovirus infections in solid organ transplantation: a review. Infect Chemother. 2013;45(3):260-71.

13. Delgado JF, Manito N, Almenar L, Crespo-Leiro M, Roig E, Segovia J, et al. Risk factors associated with cytomegalovirus infection in heart transplant patients: a prospective, epidemiological study. Transpl Infect Dis. 2011;13(2):136-44.

14. Mendez-Eirin E, Paniagua-Martín MJ, Marzoa-Rivas R, Barge-Caballero E, Grille-Cancela Z, Cañizares A, et al. Cumulative incidence of cytomegalovirus infection and disease after heart transplantation in the last decade: effect of preemptive therapy. Transpl Proc. 2012;44(9):2660-2.

15. Costanzo MR, Dipchand A, Starling R, Anderson A, Chan M, Desai S, et al. The International Society of Heart and Lung Transplantation guidelines for the care of heart transplant recipients. J Heart Lung Transpl. 2010;29(8):914-56.

16. Horan TC, Andrus M, Dudeck MA. CDC/NHSN surveillance definition of health care-associated infection and criteria for specific types of infections in the acute care setting. Am J Infect Control. 2008;36(5):309-32

17. Husain S, Mooney ML, Danziger-Isakov L, Mattner F, Singh N, Avery R, et al. A 2010 working formulation for the standardization of definitions of infections in cardiothoracic transplant recipients. J Heart Lung Transpl. 2011;30(4):361-74

18. Humar A, Michaels M, AST ID Working Group on Infectious Disease Monitoring. American society of transplantation recommendations for screening, monitoring and reporting of infectious complications in immunosuppression trials in recipients of organ transplantation. Am J Transpl. 2006;6(2):262-74.

19. Magiorakos A-P, Srinivasan A, Carey RB, Carmeli Y, Falagas ME, Giske CG, et al. Multidrug-resistant, extensively drug-resistant and pandrugresistant bacteria: an international expert proposal for interim 
standard definitions for acquired resistance. Clin Microbiol Infect. 2012;18(3):268-81.

20. Ljungman $P$, Boeckh $M$, Hirsch HH, Josephson F, Lundgren J, Nichols G, et al. Definitions of cytomegalovirus infection and disease in transplant patients for use in clinical trials. Clin Infect Dis. 2017;64(1):87-91.

21. Kobashigawa J, Zuckermann A, Macdonald P, Leprince P, Esmailian F, Luu $M$, et al. Report from a consensus conference on primary graft dysfunction after cardiac transplantation. J Heart Lung Transpl. 2014;33(4):327-40.

22. Billingham M, Kobashigawa JA. The revised ISHLT heart biopsy grading scale. J Heart Lung Transpl. 2005;24(11):1709.

23. Grossi P, De Maria R, Caroli A, Zaina MS, Minoli L. Infections in heart transplant recipients: the experience of the Italian heart transplantation program. Italian Study Group on Infections in Heart Transplantation. J Heart Lung Transpl. 1992;11(5):847-66.

24. Montoya JG, Giraldo LF, Efron B, Stinson EB, Gamberg P, Hunt S, et al. Infectious complications among 620 consecutive heart transplant patients at Stanford University Medical Center. Clin Infect Dis. 2001;33(5):629-40.

25. Rostad CA, Wehrheim K, Kirklin JK, Naftel D, Pruitt E, Hoffman TM, et al. Bacterial infections after pediatric heart transplantation: epidemiology, risk factors and outcomes. J Heart Lung Transpl. 2017;36:996-1003.

26. Rodríguez $C$, Muñoz P, Rodríguez-Créixems M, Yañez JF, Palomo J, Bouza E. Bloodstream infections among heart transplant recipients. Transplantation. 2006;81(3):384-91.

27. Hsu R-B, Chang C-I, Fang C-T, Chang S-C, Wang S-S, Chu S-H. Bloodstream infection in heart transplant recipients: 12 -year experience at a university hospital in Taiwan. Eur J Cardio Thorac Surg. 2011;40(6):1362-7.

28. Cervera C, van Delden C, Gavaldà J, Welte T, Akova M, Carratalà J, et al. Multidrug-resistant bacteria in solid organ transplant recipients. Clin Microbiol Infect. 2014;20(Suppl 7):49-73.

29. Russo MJ, Iribarne A, Hong KN, Ramlawi B, Chen JM, Takayama H, et al. Factors associated with primary graft failure after heart transplantation. Transplantation. 2010;90(4):444-50.
30. D'Alessandro C, Golmard J-L, Barreda E, Laali M, Makris R, Luyt C-E, et al. Predictive risk factors for primary graft failure requiring temporary extracorporeal membrane oxygenation support after cardiac transplantation in adults. Eur J Cardio Thorac Surg. 2011;40(4):962-9.

31. Agence de la biomédecine - Le rapport annuel médical et scientifique. 2015. [cited 2017 Jun 19]. https://www.agence-biomedecine.fr/annexes/ bilan2015/donnees/organes/03-coeur/synthese.htm.

32. Segovia J, Cosío MDG, Barceló JM, Bueno MG, Pavía PG, Burgos R, et al. RADIAL: a novel primary graft failure risk score in heart transplantation. J Heart Lung Transpl. 2011;30(6):644-51.

33. Hong KN, Iribarne A, Worku B, Takayama H, Gelijns AC, Naka Y, et al. Who is the high-risk recipient? Predicting mortality after heart transplant using pretransplant donor and recipient risk factors. Ann Thorac Surg. 2011;92(2):520-7 (discussion 527)

34. Tissot F, Pascual M, Hullin R, et al. Impact of targeted antifungal prophylaxis in heart transplant recipients at high risk for early invasive fungal infection. Transplantation. 2014;97:1192-7. https://doi.org/10.1097/01. tp.0000441088.01723.ee.

35. Johansson I, Andersson R, Friman V, Selimovic N, Hanzen L, Nasic S, et al. Cytomegalovirus infection and disease reduce 10-year cardiac allograft vasculopathy-free survival in heart transplant recipients. BMC Infect Dis. 2015;24(15):582.

36. Kobashigawa J. Clinical trials in heart transplantation: the evolution of evidence in immunosuppression. J Heart Lung Transpl. 2017;36(12):1286-90

37. Gupta R, Schlendorf K, Lindenfeld J. Older and wiser: personalized Immunosuppression in the Current Era. JACC Heart Fail. 2017;5(12):943-5.

38. Lund LH, Edwards LB, Kucheryavaya AY, Dipchand Al, Benden C, Christie $J D$, et al. The registry of the international society for heart and lung transplantation: thirtieth official adult heart transplant report-2013; focus theme: age. J Heart Lung Transpl. 2013;32(10):951-64.

\section{Submit your manuscript to a SpringerOpen ${ }^{\circ}$ journal and benefit from:}

- Convenient online submission

- Rigorous peer review

- Open access: articles freely available online

- High visibility within the field

- Retaining the copyright to your article

Submit your next manuscript at $\boldsymbol{\nabla}$ springeropen.com 